Running Head: SOCIAL SEMANTICS

\title{
Social Semantics: The role of conceptual knowledge and cognitive control in a neurobiological model of the social brain
}

\author{
Richard J. Binney ${ }^{1 *}$ and Richard Ramsey ${ }^{1,2^{*}} \dagger$
}

\begin{abstract}
${ }^{1}$ Wales Institute for Cognitive Neuroscience, School of Psychology, Bangor University
${ }^{2}$ Department of Psychology, Macquarie University

† The two authors made an equal contribution to this manuscript.
\end{abstract}

\section{*Address Correspondence to:}

Richard J. Binney, PhD or Richard Ramsey, PhD

Wales Institute for Cognitive Neuroscience

School of Psychology

Bangor University

Gwynedd, LL57 2AS

Wales, UK

Email: R.Binney@Bangor.ac.uk/R.Ramsey@Bangor.ac.uk

Tel: +44 (0) 1248383478

Acknowledgements: The authors would like to thank Robert Ward and Emily S. Cross for their comments on a previous version of this manuscript.

Disclosure: The authors declare no potential conflicts of interest.

Word Count (not including abstract): 7569

Abstract Word Count: 169

Number of Figures: 2

Number of Tables: 0 


\section{Abstract}

Research in social neuroscience has primarily focused on carving up cognition into distinct pieces, as a function of mental process, neural network or social behaviour, while the need for unifying models that span multiple social phenomena has been relatively neglected. Here we present a novel framework that treats social cognition as a case of semantic cognition, which provides a neurobiologically constrained and generalizable framework, with clear, testable predictions regarding sociocognitive processing in the context of both health and disease. According to this framework, social cognition relies on two principal systems of representation and control. These systems are neuroanatomically and functionally distinct, but interact to (1) enable development of foundational, conceptual-level knowledge and (2) regulate access to this information in order to generate flexible and context-appropriate social behaviour. The Social Semantics framework shines new light on the mechanisms of social information processing by maintaining as much explanatory power as prior models of social cognition, whilst remaining simpler, by virtue of relying on fewer components that are "tuned" towards social interactions.

Key words: social cognition; control; representation; semantic cognition; cognitive neuroscience. 


\section{Introduction}

The neuroscientific study of social cognition and social behaviours is now undoubtedly one of the most rapidly developing domains of systems neuroscience, and in recent years, its influence has spread to have impact upon fields ranging from psychiatry to behavioural economics (Adolphs, 2009; Cacioppo and Berntson, 1992; Cacioppo and Decety, 2011; Frith and Frith, 2011; Lieberman, 2006). Like any developing research programme, sub-fields within social neuroscience have emerged, which specialise in perceptual, cognitive, emotional and regulatory functions and their associated neural substrates (Adolphs, 2010). Further, within each of these sub-fields, an increasing number of distinct phenomena are being identified as worthy of investigation. Indeed, as is the case with psychology and neuroscience more generally, the dominant approach has been to carve up social cognition into distinct pieces, as a function of mental process, neural network or social behaviour.

The focus on compartmentalising social cognition according to a range of distinct organising principles has made a valuable contribution to understanding the cognitive and neural bases of social cognition. At the same time, the need for unifying models that span multiple social phenomena, and offer a generalizable framework (Adolphs, 2010), has been relatively neglected. We argue that progress on key questions in social neuroscience will be optimised if broader frameworks for considering cognition in general are considered together with developments made in sub-fields of social cognition. Therefore, the aim of the present paper is to show how a parallel line of literature, which is usually considered more relevant to the cognitive neuroscience of language and object knowledge, has established foundational principles that can inform social neuroscience theory. In fact, we will argue that upon closer inspection, the two seemingly distinct domains appear to dovetail in terms of the processes they describe 
and the brain regions they implicate. As such, by taking inspiration from the semantic cognition literature, the current paper is able to offer an exciting new direction for social neuroscience theory, which is predicated on a wealth of evidence and offers a point of departure from existing approaches to understanding the social brain.

One of cognitive neuroscience's most successful theoretical perspectives in recent years is the controlled semantic cognition (CSC) framework (Lambon Ralph et al., 2016). The proponents of CSC use the term 'semantic cognition' to describe a set of supramodal processes that underpin how meaning is gathered from the environment. These processes include the distillation of verbal and non-verbal experiences to form a coherent knowledge base of the meaning of words, objects, people and events. Moreover, this foundation of conceptual knowledge is regulated by a supervisory system that supports interactions with our environment (including other agents within it) to occur in a flexible manner, as well as in a controlled, and context-appropriate manner.

Whilst the term 'semantics' is more frequently associated with language abilities, according to the CSC framework, a central semantic system is key not only to comprehension and production of verbal behaviours, but also to nonverbal behaviours including action perception (Caspers et al., 2010; Davey et al., 2015), object interactions (Bar, 2004; Corbett et al., 2009; Culham and Valyear, 2006), and a range of sociocognitive processes, including person identification (Kanwisher, 2010; Rice et al., 2018b), empathy, and emotion recognition (Adolphs, 2002; Binney et al., 2016a; Singer and Lamm, 2009). The predictions of the framework are supported by over a decade's worth of multi-method research, and its great appeal lies in the fact in that it offers both a relatively straight-forward computational model with clear neurobiological constraints, as well as clinically-relevant hypotheses. 
In the current paper, we outline how the CSC framework can be broadly transposed into the domain of social cognition. Going even further, we propose that it is constructive to describe social cognition as a case of semantic cognition, which means we expect it to operate under the same basic principles (i.e., a bipartite distinction between representation and control processes). As such, in the following sections, we first describe the key components of the CSC framework, and then briefly review some existing research that has begun to link it to the neurobiology of socio-affective behaviour. Second, we propose some modifications of the CSC framework that explicitly link it to social phenomena, and then compare it with other models of social cognition, highlighting key distinctions, relative strengths and possible weaknesses. Finally, we consider how operationalising social cognition under a modified CSC framework can guide and inform a range of future research avenues. The impact on future research includes understanding the neurocognitive mechanisms that underpin social interactions, as well as the emergence and development of these systems, and the biological underpinnings of clinical conditions whose symptoms are typified by disordered social information processing (e.g., Autism Spectrum Conditions and Schizophrenia).

\section{Basic principles of the CSC framework}

The CSC framework has two principal neural systems. The first is representational in nature, and supports the acquisition and long-term storage of conceptual knowledge (Figure 1A). The second system is responsible for control processes that manipulate semantic information and utilise this information in line with task- and context-specific requirements (Figure 1B). As we discuss below, a growing body of multi-method 
evidence supports claims for the existence of these two distinct but interacting semantic sub-systems (Lambon Ralph et al., 2016).

The CSC framework characterises the semantic representational system as having a hub-and-spoke architecture (Figure 1A). This refers to the idea that modalityspecific systems distributed across the brain (the 'spokes') play an essential role in supplying the information required to establish concepts, namely our multimodal sensorimotor, linguistic, and affective experiences of concept exemplars. This notion of 'embodiment' is shared among a number of contemporary neurobiological accounts of semantic memory (e.g., Martin, 2006). However, the CSC framework is fundamentally different to prior embodied accounts, in that it argues for the necessity of an additional, supramodal hub. The supramodal hub serves two functions: 1) it mediates transmodal interactions between different modes of input from the 'spokes' and 2) it encodes a deeper level of representation that abstracts beyond a linear combination of such inputs from the 'spokes'. This deeper and more abstract level of representation is argued to be critical for the production of generalizable concepts. Moreover, whilst the supposition of an existence of multiple transmodal 'convergence zones' appears within other accounts of higher-order cognition (e.g., Damasio et al., 1996), the claim that a central semantic hub is responsible for encoding all types of concepts (including knowledge of concrete objects and more abstract conceptual constructs) is the hallmark feature of the CSC framework. In particular, it holds that this principal hub is located within the bilateral anterior temporal lobes (ATL; see Figure 1).

The ATL hub hypothesis has been principally driven by cognitive neuropsychology and, in particular, the detailed study of patients with a disorder known as semantic dementia (SD). SD patients present with a progressive yet highly selective central impairment of semantic memory. The deficits are evident in both expressive and 
A. The hub-and-spoke architecture of semantic representation
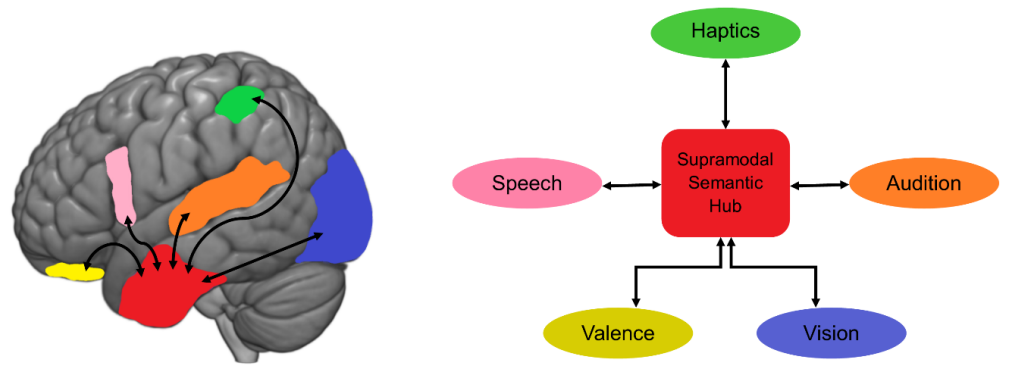

B. The supramodal semantic network (and MDN)

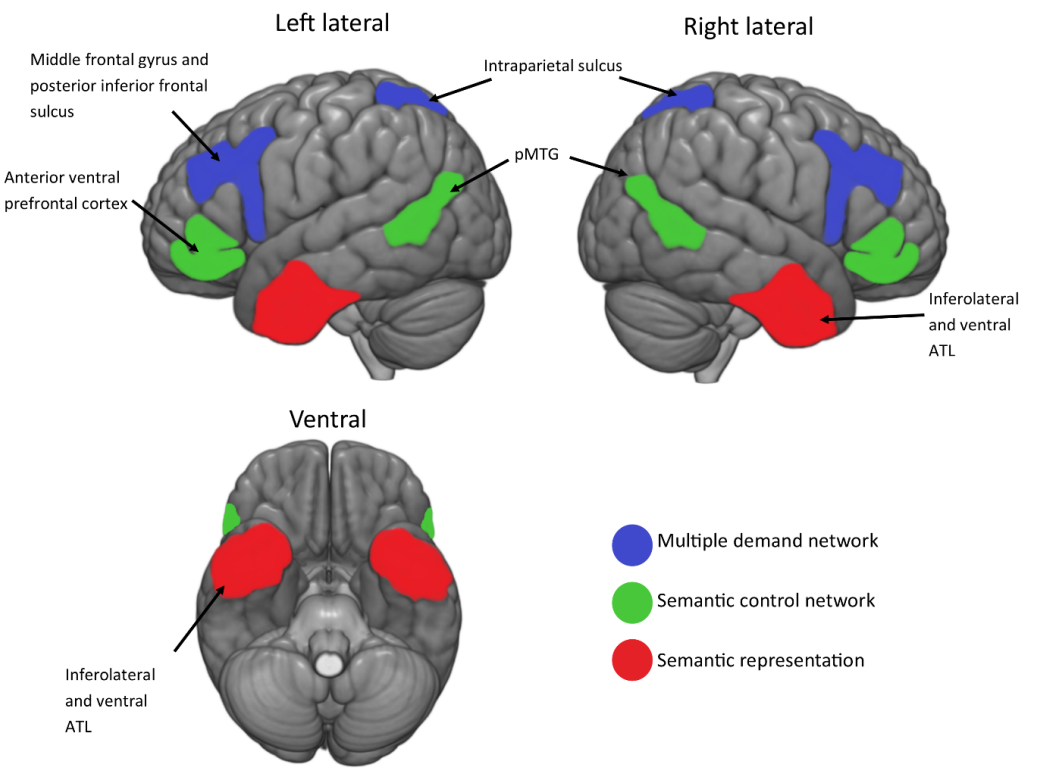

C. The social network
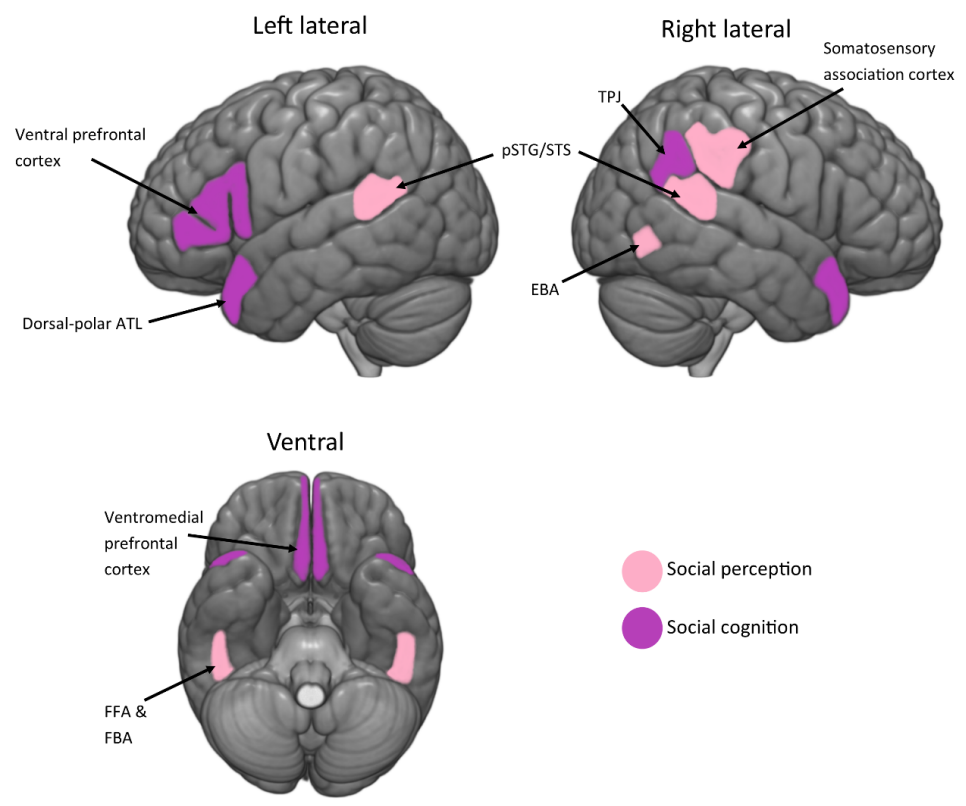

Social perception

Social cognition
Figure 1. Brain networks associated with semantic and social cognition.

This figure contains simplified schematics of the brain networks purported to be involved in semantic and social cognition. Panel A illustrates the putative hub-andspoke architecture of semantic representation, and highlights contributions of both modalityspecific association cortex, and a supramodal semantic 'hub' located in the bilateral anterior temporal lobes. Although not shown here, we acknowledge that medial frontal and parietal association cortex (e.g., the cingulate and precuneus) may also contribute as 'spoke' regions. Panel B illustrates the broader supramodal semantic network, which comprises the anterior temporal hub, and frontal and posterior temporal regions implicated in semantic control processes (Lambon Ralph et al., 2017). This is contrasted against regions hypothesised to comprise a domain-general multiple-demand network (MDN; Duncan, 2010). Note that not all regions of the DMN are shown, and some regions overlap with those of the semantic control network (see text for more details). Panel C illustrates lateral and ventral brain regions associated with social perceptual and cognitive processes. This network is also thought to include medial structures such as the dorsomedial prefrontal cortex (Adolphs, 2010). 
receptive semantic tasks, across all modalities including spoken and written language, object use, picture-based tasks, environmental sound tasks, and in olfaction and taste (Bozeat et al., 2000; Coccia et al., 2004; Lambon Ralph et al., 2001; Luzzi et al., 2007; Piwnica-Worms et al., 2010). Strikingly, other perceptual and cognitive faculties, such as phonology, executive skills and memory for recent events, remain largely unaffected (Gorno-Tempini et al., 2011; Hodges et al., 1992; Irish et al., 2011).

The SD syndrome falls within the spectrum of frontotemporal dementia (FTD) and is coupled with relatively focal atrophy and hypometabolism centred on the polar and ventrolateral aspects of the bilateral anterior temporal lobes (Mummery et al., 2000; Nestor et al., 2005). The body of evidence for a role of the ATL as a semantic hub is now extensive and includes convergent observations from functional neuroimaging (e.g. PET and fMRI), direct intracranial recording, and also neuromodulation (TMS/tDCS) studies of neurotypical adults (Binney et al., 2018, 2016b, 2010; Binney and Lambon Ralph, 2015; Chan et al., 2011; Hoffman et al., 2015; Mion et al., 2010; Pobric et al., 2007; Shimotake et al., 2015). While the CSC framework asserts that the ATL hub is a crucial contributor, it does not assert that conceptualization can be achieved solely by reactivation of the representations served by the hub. Instead, in the model instantiated computationally by (Rogers et al., 2004), the hub and spokes are bi-directionally connected and complete conceptualization arises from the conjoint computations of both the hub and all the distributed 'spokes'. Observations from both TMS and fMRI studies support this notion (Guo et al., 2013; Pobric et al., 2010; Reilly et al., 2016). The second tenet of the CSC framework is that the successful application of conceptual knowledge (i.e., the generation of meaningful behaviour) requires mechanisms that control access to our knowledge. This is necessary because our extensive and varied experiences of words, people and objects result in deep and 
complex representations, and in many circumstances, we need only to retrieve a few details. Indeed, automatically retrieving all aspects of our knowledge would be computationally expensive and might be inappropriate and/or interfere with our ability to achieve our goals. For example, the pianist need not retrieve all their expert knowledge of how to use their instrument to play a concerto, should, in the very moment, their only task be to move it across the stage (Saffran, 2000).

Control processes are therefore needed to actively shape the way we access our semantic database and ensure that only context- and task-relevant aspects of meaning are brought to the fore. There is evidence to suggest that semantic representation and semantic control can be dissociably affected by brain injury or disease. For example, Jefferies and Lambon Ralph (2006) describe a group of patients with multimodal semantic impairments following stroke who exhibit performance that is inconsistent across semantic tasks and across trials within a task, and performance that can improve considerably with the provision of contextual cues that constrain task requirements. This pattern of impairment is consistent with disordered cognitive control and is associated with damage to ventrolateral frontal and/or posterior perisylvian regions (Jefferies, 2013; Jefferies and Lambon Ralph, 2006). In contrast, SD patients are highly consistent and insensitive to cues. This is congruous with a degradation of semantic knowledge. Observations such as these support the claim that semantic representation and control are associated with distinct cortical territories.

By now a sizeable body of convergent patient, fMRI, and TMS evidence supports a role for bilateral ventrolateral prefrontal and temporoparietal cortex in shaping or regulating which aspects of meaning are retrieved in both verbal and non-verbal semantic tasks (Badre and Wagner, 2007; Noonan et al., 2009; Thompson-Schill et al., 1997; Thompson et al., 2016; Whitney et al., 2011a). Recent investigations have 
therefore begun to tease apart the individual contributions of these regions to semantic control and establish the extent to which they are distinct from domain-general executive processes (Davey et al., 2016; Devlin et al., 2003; Gough et al., 2005; Noonan et al., 2013). Indeed, the CSC framework proposes that the executive component of semantic cognition comprises both domain-general processes and processes specific to semantic memory retrieval. Domain-general control processes support goal-driven behaviour and respond to associated executive demands irrespective of the task domain (i.e., perceptual, motor or semantic; Duncan, 2010). Such processes recruit nodes of the Multiple-Demand network including the middle frontal gyrus and posterior inferior frontal sulcus and the intraparietal sulcus (Duncan, 2010). Semantic retrieval demands, however, specifically correlate with activation of more inferior structures, including the ventrolateral prefrontal cortex (particularly pars orbitalis of the inferior frontal gyrus) and the posterior middle temporal gyrus (see Figure 1B; Badre et al., 2005; Fedorenko et al., 2012; Nagel et al., 2008; Whitney et al., 2011b). CSC proponents have suggested that these additional regions in inferior frontal and posterior middle temporal gyri could play a role in mediating the interaction of domain-general control processes with the semantic representational system (Davey et al., 2016; Lambon Ralph et al., 2016).

Indeed, a final key feature of the CSC framework is that the representational and control systems do not act in isolation (Lambon Ralph et al., 2016). Instead, it has been proposed that the mature semantic system is best characterised by these two principal systems, as well as by their interaction. Initial efforts to test this proposal empirically support this idea. For example, fMRI evidence has begun to elucidate the way in which the semantic control network interacts with the hub-and-spoke architecture underpinning semantic representation; Chiou, Humphreys, Jung \& Lambon Ralph 
(2018) observed that the control system dynamically modulates its connectivity with hub and spoke regions according to semantic content and difficulty of tasks.

\section{The CSC framework and sociocognitive processing}

In this section, we apply the principles and basic architecture of the CSC framework to social information processing. Our premise is that in doing so, we can open up a new understanding of social cognition, revealing that it operates under the same basic principles as semantic cognition and that it implicates a highly overlapping, if not the same, set of brain regions (see Figure 1).

Adolphs (2010) describes three broad stages of social information processing, namely perception, cognition, and regulation. It is our assertion that these stages map transparently onto the CSC framework. Adolphs (2010) describes social perception as the transduction of social information towards a richer representation required for cognitive level processing. In other words, social perception is the sensory detection of other agents in the environment and signals from this process are used by other cognitive architectures. This is not dissimilar to the description of the role played by modality-specific spokes in the CSC framework as semantic entry/exit points that translate between sensation/motor representations and semantic knowledge (Lambon Ralph, 2014). Social perception includes the visual perception of faces and biological motion, the auditory perception of speech and paralinguistic cues, the olfactory detection of pheromones, and the somatosensation of affective touch, to name but a few of the wide array of multimodal inputs that inform our social experiences and form the building blocks of social knowledge.

Broadly speaking, the processing of each of these social perceptual signals can be subsumed under one of the spokes of the CSC framework (Figure 1), and this prompts 
interesting questions about modality specificity within social information processing. One such question concerns the degree to which brain regions engaged by social perceptual signals overlap with those engaged by perceptual processing more generally and, conversely, whether functional sub-divisions exist within modality-specific processing streams that amount to privileged pathways for socially-relevant perceptual inputs. The degree of overlap is unclear, stemming from the fact that research questions in this domain tend to emphasise divergence of function rather than convergence. Indeed, the topic of domain-specificity in social perception is subject to a rich debate that extends beyond the scope of this paper, but suffice it to say that there are certainly indications that sub-specialisations do exist (for reviews, see Adolphs, 2010; Kanwisher, 2010; Spunt and Adolphs, 2017). The CSC framework, however, is equivocal on this issue, as the structure of the overall model is not tied to the degree of domain or category-selectivity in the spokes. A further question concerns whether some spokes could be particularly important for social cognition, as compared to semantic cognition more generally. Indeed, the CSC framework acknowledges that some sources of modality-specific information (e.g., emotional valence) will be differentially important for some types of concept (e.g., abstract social concepts; Binney et al., 2016b; Crutch et al., 2013; Kousta et al., 2011; Lambon Ralph et al., 2016).

As for social cognition, Adolphs (2010) describes this as attributional and inferential processing that allows us to go beyond the present inputs and generate knowledge about something that we cannot observe directly. According to the CSC framework, abilities of this nature require access to conceptual-level information that is represented within the anterior temporal lobes (Lambon Ralph et al., 2016). Indeed, the ATL has been linked with social-affective behaviour both in humans and non-human primates (Gallate et al., 2011; Klüver and Bucy, 1939; Simmons and Martin, 2009), and 
across a range of social processes, including the attribution of mental states (Frith and Frith, 2003), morality (Moll et al., 2005) and processing of affect (Wicker et al., 2003). Regarding humans, there is limited evidence from fMRI (owed, at least in part, to technical challenges associated with obtaining BOLD signal from this region; Binney et al., 2016b), but this is bolstered by descriptions of FTD patients that associate ATL atrophy with profound disturbances in social behaviour including blunted affect, decreased empathy and deficits in receptive emotional processing (Chan et al., 2009; Edwards-Lee et al., 1997; Perry et al., 2001). These observations have prompted several research groups to propose that the ATL plays a domain-specific role in the representation of social knowledge, including person knowledge, emotions, and other more abstract social concepts (Olson et al., 2013; Thompson et al., 2003; Zahn et al., 2007). See Leshinskaya et al. (2017) for a discussion regarding a possible role of a nonATL region in social conceptual representation.

Research efforts aimed at delineating the functional properties of the ATL have recently begun to ask if, and how, the purported roles of the ATL in both social and semantic processes can be reconciled under a single unifying framework (Binney et al., 2016b; Rice et al., 2018b). Some clues already existed within classic comparative neurological studies of bilateral, full depth ATL resection in non-human primates (Brown and Schafer, 1888; Klüver and Bucy, 1939) which, in the contemporary literature, are most commonly cited for post-operative changes in social behaviour. The original aims of these studies, however, were to establish whether bilateral ATL lesions led to associative as opposed to apperceptive visual agnosia. Indeed, they did, but Klüver and Bucy (1939) also noted that in addition to having acquired an inability to generate the meaning of visual stimuli, the primates could also no longer understand familiar auditory stimuli. As such, Klüver and Bucy observed a symptom complex comprising 
multimodal semantic impairments, plus additional social-affective disturbances, that closely mirror those observed in semantic dementia.

What appears, therefore, to be a pervasive coupling of semantic and social impairment in the context of bilateral ATL damage is highly suggestive of a more general semantic contribution of the ATL. Indeed, a general semantic contribution would predict that the ATL plays a role in activation of all conceptual information, including that which is socially-relevant. However, it is also possible that the bilateral ATLs comprise a domain-general semantic hub, plus other sub-regions with functional specialisations that are relatively more attuned to certain types of knowledge (Gainotti, 2015; Skipper et al., 2011). Indeed, proponents of the CSC framework have recently argued that there are graded differences in the relative specialisation of semantic function across the bilateral ATL (Lambon Ralph et al., 2016; Rice et al., 2015). This is hypothesised to arise from differential connectivity to each of the modality-specific spokes (Binney et al., 2012; Jung et al., 2017; Plaut, 2002).

According to the "graded" hub-and-spoke model, a ventrolateral ATL region (comprising the anterior fusiform and inferior temporal gyri) is hypothesised to be the centre-point of the semantic hub. This region has a supramodal, and domain/categorygeneral semantic function (Abel et al., 2015; Binney et al., 2016b, 2010; Chan et al., 2011; Hoffman et al., 2015; Shimotake et al., 2015). Away from this point, peripheral ATL sub-regions have stronger connectivity to certain modality-specific systems, and their responses to semantic tasks are more nuanced. For example, recent fMRI studies suggest that while the ventrolateral ATL responds equally to all types of concepts, the dorsal-polar ATL is more tuned to social stimuli (Binney et al., 2016b; Rice et al., 2018b). This may follow from this subregion's close proximity to and strong connectivity with the limbic system (via the uncinate fasciculus; Bajada et al., 2017; Binney et al., 2012; 
Papinutto et al., 2016), and could reflect a specialisation in the assimilation of emotionrelated information into coherent semantic representations (Olson et al., 2007; Rice et al., 2015; Vigliocco et al., 2013).

A related debate concerns the possible lateralisation of ATL involvement in social versus general semantic cognition (Gainotti, 2015). For example, it has been proposed that the right ATL is specialised for social semantic processing (Zahn et al., 2009). There is limited fMRI evidence to support this claim (e.g., Zahn et al., 2007) but more compelling is the observation that socio-affective impairments in semantic dementia are often more pronounced when the typically asymmetric patterns of bilateral ATL atrophy are greater in the right than the left hemisphere (Chan et al., 2009; Edwards-Lee et al., 1997; Perry et al., 2001). However, an elegant longitudinal patient study by Kumfor et al. (2016) revealed that increasing levels of behavioural impairment correlate with the progression of atrophy in both the left and right ATL. Even more problematic for claims of social domain-specificity is a recent meta-analysis of fMRI studies (Rice et al., 2015) and two further original studies (Binney et al., 2016b; Rice et al., 2018b) that reveal a) bilateral ATL involvement in processing non-social stimuli and b) very little evidence of asymmetric ATL activations to social stimuli. This does not preclude, though, the possibility of graded differences in sensitivity to social information across the left and right ATL (Binney et al., 2016a; Pobric et al., 2015; Snowden et al., 2018). A rightwards bias in this regard could conceivably arise from a division of labour in the representation of certain types of conceptual information or from greater proximity and greater connectivity to certain right-lateralised and socially-salient perceptual pathways such as that involved in face perception (Coad et al., 2017; Gainotti, 2015; Hoffman and Lambon Ralph, 2018; Papinutto et al., 2016; Rice et al., 2018a; Von Der Heide et al., 2013). 
As far as we aware, to date, no explicit attempts have been made to determine whether regions that respond to semantic control demands (i.e., the anterior IFG and the posterior MTG) are similarly engaged by the types of tasks and stimuli employed within the social neuroscientific literature. Thus, it remains to be seen how well the control component of the CSC framework maps onto social 'regulation' (Adolphs, 2010). In the next two sections, we discuss how key research questions that pertain to social control might follow along similar lines to the principles explored above in the context of social perception and social cognition. That is, we raise the issue of specificity of purported function (e.g., is a regional response related to general cognitive function, a general semantic function, or a domain-specific, social semantic function?) and whether such a distinction should be considered absolute or graded in nature.

\section{How does the CSC framework compare to other models of social cognition?}

To further contextualise our proposed application of the CSC framework to account for social behaviours, we compare its features with those of other prominent models of social cognition. Moreover, we compare it to two types of existing model. First, we contrast it against broad models of social cognition that outline general principles that should apply across a range of sociocognitive processes (e.g., Adolphs, 2009; Frith and Frith, 2011; Lieberman, 2006). This enables a cross-examination of high-level assumptions regarding key organisational principles of social cognition, and brain function more generally. Second, we compare tenets of our model to those that have emerged from within a specific domain of social cognition, namely the phenomenon of 'automatic imitation' (Brass et al., 2009; Brass and Heyes, 2005; Darda et al., 2018; de Guzman et al., 2016; Gowen and Poliakoff, 2012; Heyes, 2011; Ramsey, 2018; Sowden and Shah, 2014; Spengler et al., 2009; Wang and Hamilton, 2012). We have chosen to 
focus on automatic imitation partly for convenience, in that we have experience in this area of research, but also because it provides a specific concrete example of how the general principals of the model can be applied within a specific research context.

Before going further, it is important to highlight one general distinction between the model put forward here and prior models of social cognition, which is that we start from a position of proposing that social cognition is a case of semantic cognition. We are therefore arguing against claims that social cognition is a special or distinct case of cognition. Instead, we suggest that social information processing is just one way of gathering meaning from the environment. The implication here is that social cognition will rely on the same basic cognitive and brain mechanisms as semantic cognition, which includes a sub-system of conceptual representation (the hub and the spokes) and another of control. Existing models of social cognition, whether pitched at a general level or more specifically tied to a particular aspect of social processing (e.g., imitation), have different starting points. Indeed, the key driving force for most has been to characterise mechanisms that are specialized towards social information processing. We argue that this new conceptualisation, which places greater emphasis on more general mechanisms, holds potential to shine new light on the possible structure of the cognitive and neurobiological mechanisms that underpin social information processing.

\subsection{A comparison of the CSC framework to general models of social cognition}

As outlined in Sections 2 and 3, the CSC framework makes a clear distinction between representation and control, both in terms of cognitive processes and associated neural networks. Most general models of social cognition place little, if any, emphasis on this differentiation (Adolphs, 2009; Frith and Frith, 2011, 2010; Lieberman, 2006). Further, prior models have only briefly touched upon the contribution of executive 
processes to social behaviour. For example, Frith \& Frith (2011) briefly refer to a "supervisory system" (Beck and Kastner, 2009), which has the hallmarks of executive control, but is otherwise under-specified. Likewise, Adolphs (2009) refers to cognitive control and the engagement of lateral prefrontal cortex, but again, it receives a secondary focus. Moreover, the anatomical specificity of such a supervisory system is lacking. The result is a nebulous construct of social regulation, and a lack of indication as to whether it is underpinned by systems that are specialised to support social information processing, by more domain-general mechanisms, or by a combination of both types of mechanism.

This state of understanding the systems underpinning social control stands in stark contrast to discussions surrounding social perception and social cognition where great care has been taken to a) define what is socially-relevant information (e.g. pheromones) and what is not, and b) test the extent to which processing this information relies on a specialised set of neural circuits (e.g., person perception in the ventral visual stream, the 'mirror neuron' system, and the putative 'theory of mind' network; e.g., Adolphs, 2010; Kanwisher, 2010). For a field that has emerged over the past 25 years, this makes sense as a place to start, in terms of establishing the face validity of social cognition as a unique entity to other general forms of cognition. However, by neglecting to also consider the contributions of more domain-general systems to both the representation of social knowledge, and to the regulation of the way we implement this knowledge, these broad models of social cognition may have unintentionally limited their explanatory power. Indeed, we propose that a more comprehensive model of social cognition can only be realised with the concurrent consideration of contributions from both domain-general and domain-specific resources. Moreover, we propose that it is essential to delineate and understand the 
contributions of both representational and control systems, and the interactions between them.

Rather than frame a putative distinction as one of representation and control, prior models of social cognition have often juxtaposed controlled processes against automatic processes (Adolphs, 2009; Frith and Frith, 2011; Lieberman, 2006). Typically, automatic processes are characterised as fast, efficient and unintentional, and are contrasted against controlled processes which are slower, less efficient and more deliberate (Posner and Snyder, 1975; Shiffrin and Schneider, 1977). These "dualsystems" approaches have been influential in developing the modern understanding of cognition, but, equally, they have been criticised for oversimplifying both the distinction and relationship between automaticity and control (Bargh, 1994, 1989; Melnikoff and Bargh, 2018; Moors and De Houwer, 2006).

In contrast, we propose that the degree to which behaviours have particular attributes (e.g., speed, efficiency, or intentionality), does not simply reflect the preponderance of one mechanism over the other but, instead, a qualitative difference in the degree to which control needs to be imposed on activation within the representational system. For instance, when looking for a friend at a crowded train station, cognitive control resources would upregulate the importance of face and body feature detection processes that predominantly occur in the 'spokes'. However, when waiting for a train at a crowded station, attentional resources would prioritise the detection of moving objects rather than faces and body parts, thus leaving face and body-selective modules to operate in a more stimulus-driven and automatic way. As an alternative example, when faced with the task of evaluating the commonalities between two familiar persons, our conclusions would be quite different when we base the comparison on, subjectively speaking, the most salient and thus automatically-retrieved 
features (e.g., their professional relationship to us) versus more latent features (e.g., their personal values and hobbies). Therefore, depending on the social context, there is a need to exert quantitatively stronger control influences to inhibit the retrieval of certain aspects of representational content. In addition, there might also be a need for qualitatively different kinds of control, such as control exerted through domain-general resources in some contexts, but semantic control resources in other contexts (Ramsey, 2018). In all contexts, however, we suggest that the processing of social information would require some degree of representational input and some form of cognitive control. Therefore, following precedent in the domain of theory-of-mind (Carruthers, 2017, 2016), we are proposing a single route architecture that has as much explanatory power as the dual-route approaches previously outlined.

Our proposal has some overlap with those put forward by others recently (Amodio, 2019; Kilner, 2011; Spunt and Adolphs, 2017), all of which emphasise the consideration of parallel literatures for understanding mechanisms of social information processing. For example, partly based on principles developed in models of memory (Cabeza and Moscovitch, 2013), Spunt and Adolphs (2017) argue that social cognition may be made up of multiple component pieces, and not all of them need to be domainspecific. Moreover, Amodio (2019) argues that models of impression formation can be constrained by the way types of memory rely on functionally and anatomically distinct systems. Of particular note for our proposal, is Kilner's (2011) suggestion that understanding of the meaning of observed actions is mediated by a semantic retrieval pathway between anterior IFG and posterior MTG. Indeed, this is consistent with our suggestion that social regulation, or social control, is underpinned by the very same brain systems that support semantic control more generally. An implication of these combined perspectives is that existing models within parallel domains of cognition may 
provide more fertile ground for building models of social cognition than is currently afforded by building them as a distinct or even special case.

To be clear, though, we are not suggesting that processing social information does not impose exceptional demands on cognition. To the contrary, we acknowledge that many social signals are amongst the most complex stimuli to interpret. What we are instead suggesting is that processing social information may differentially engage certain parts of the semantic system, such that graded differences will emerge in the responses of the associated neural network to more or less socially-relevant tasks. As we discussed in the previous section, evidence already exists to support this notion, and in particular that of a graded representational semantic hub in the bilateral ATLs that comprises pan-category general semantic function in the ventrolateral area and more nuanced social semantic function within the temporopolar cortex (Binney et al., 2016b; Rice et al., 2018b)

\subsection{A comparison of the CSC framework to models of automatic imitation}

Our model emphasises a more generalizable set of multiple demand and semantic control processes (Figure 2A), rather than any form of social domain-specific control as proposed in models of automatic imitation and processes associated with regulating self-other processes (Brass et al., 2009; Sowden and Shah, 2014; Spengler et al., 2009; Wang and Hamilton, 2012). Indeed, as briefly discussed above, the starting point of the current model is that we should expect the control of social representations to be identical in structure to the control of non-social representations. For example, sitting down on a chair will involve visual and motoric representations, plus a sense of timing, all constrained by a relatively stable context (e.g., the chair's condition). These visual and motoric representations would need to be appropriately controlled to successfully 
carry out the action. Likewise, interacting with a person, in terms of cognitive systems, may be no different. We have a set of person representations - visual, motoric, affective - which need controlling in reference to an interpersonal context that may be constantly-shifting (e. g., a colleague's evolving perspective of an argument you are delivering).

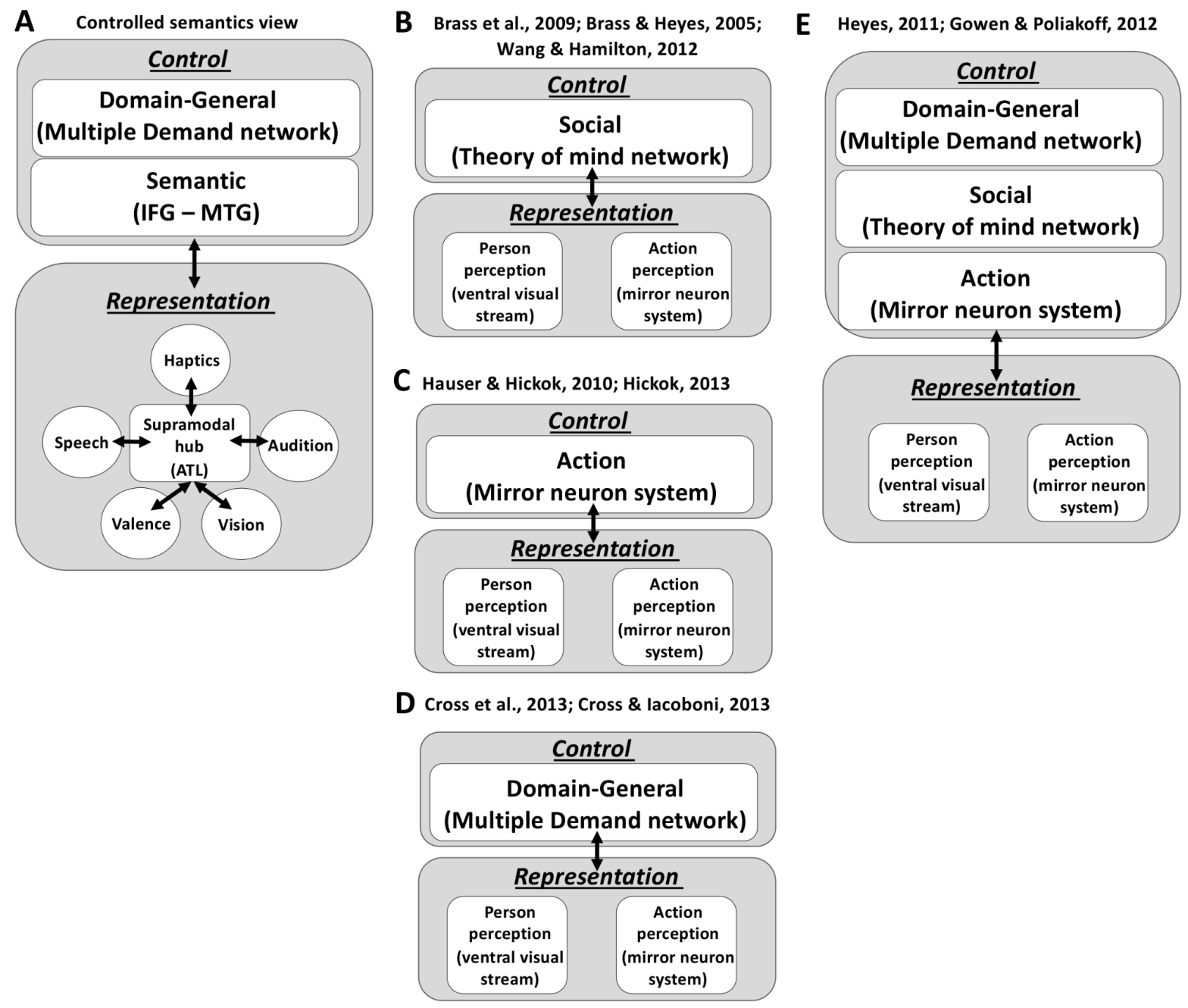

Figure 2. Models of social information processing in the control of automatic imitation.

When considering the evidence for or against this model, it is important to be mindful of the difference between stimulus-specificity and mechanism-specificity (Adolphs, 2009). For example, there is a large body of evidence to support the existence 
of brain regions that are relatively specialised for the social information represented by faces, bodies, voices and for reasoning about others' mental states (Kanwisher, 2010). These regions appear distinct from those associated with processing objects (Bar, 2004), tools (Culham and Valyear, 2006), places (Epstein et al., 1999) and written words (Dehaene and Cohen, 2011). This suggests a degree of stimulus specificity in detecting aspects of the social vs. non-social environment. However, less evidence exists for mechanism-specificity in terms of controlling the activation associated with such social representational content. On the contrary, considerable evidence exists to support the involvement of more domain-general control systems that span frontoparietal cortices (Badre, 2008; Corbetta et al., 2008; Corbetta and Shulman, 2002; Desimone and Duncan, 1995; Duncan, 2010; Miller, 2000).

In the context of research concerning automatic imitation, several forms of domain-specific control or "social control" have been proposed (Figure 2B). For example, Brass and colleagues (2009) suggest that a brain circuit believed to be involved in mental state attribution is engaged when imitative tendencies need controlling during social interactions (see also Brass and Heyes, 2005; Spengler et al., 2009; Wang and Hamilton, 2012). More specifically, Brass and colleagues (2009) suggest that anterior medial prefrontal cortex (mPFC) and right temporoparietal junction (rTPJ), two key nodes of the putative theory of mind network (Frith and Frith, 1999; Saxe and Kanwisher, 2003; Van Overwalle, 2009), regulate social interactions through a process of self-other distinction. In other words, it is claimed that by separating self from other during social exchanges, mPFC and rTPJ play an important role in the regulation of social interactions.

Based on the initial work by Brass and colleagues (Brass et al., 2009; Brass and Heyes, 2005; Spengler et al., 2009), which provided the first account of "social control" 
in automatic imitation, several variants based on this theme have followed. For instance, Wang \& Hamilton (2012) have suggested that social control is governed through the theory of mind network exerting a top-down influence on other neural networks associated with social cognition. By contrast, other researchers have proposed that a process of self-other distinction, which is underpinned by rTPJ, is engaged in a more elaborate set of social cognitive functions, which extend beyond imitation, and include perspective-taking, empathy and theory of mind (de Guzman et al., 2016; Sowden and Shah, 2014). Moreover, disruption to this process has been proffered as an important contributing factor to social disorders such as ASD (de Guzman et al., 2016). An alternative domain-specific proposal suggests that the control of imitation relies on the operations of the mirror neuron system (Figure 2C; Hickok, 2013; Hickok and Hauser, 2010). The mirror neuron system is activated during the performance and observation of action and has previously been suggested to be involved in imitation (Iacoboni, 2008). These accounts all suggest that there exists a specialised control circuit for regulating interactions with other people.

Some other proposals leave open the possibility for a contribution of domaingeneral control in imitation (Figure 3D; Cross et al., 2013) or a combination of both forms of control - domain-general and domain-specific (Figure 3E; Cross et al., 2013; Gowen and Poliakoff, 2012; Heyes, 2011). For example, Gowen and Poliakoff's (2012) model includes a role for $\mathrm{mPFC}$ in regulating similarity to self, a process specific to social cognition, whereas lateral prefrontal cortices are involved in more domain-general processes including the regulation of attention and inhibitory control. The implication here, and one that we advocate, is that should specialized control mechanisms exist, they will be nested among and complement more general executive processes. 
One of the key arguments of our proposal is that the field needs to prioritise investigating how far models of social cognition get when they use broad and encompassing definitions of executive and representational systems that have been established across other domains. It is our view that before claims can be made about the existence of, or need for, social domain-specific control processes, future empirical work must first firmly establish that domain-general and semantic control processes are insufficient to account for the social psychological phenomenon at hand. To this end, experimental designs should always attempt to dissociate the social aspect of an experiment from the other key manipulations (e.g., executive load) and, for example, establish an interaction wherein the effect of interest (be it behavioural or physiological) is only present when the task or stimuli are socially-relevant. Furthermore, we believe that it is essential that the generality of an effect is comprehensively explored by testing over a wide range of experimental paradigms and using a variety of measures (behavioural and brain-based) and populations (neurotypical and clinical). This serves to avoid unnecessary fractionation and an explosion of putative control processes, which serve all manner of conceivable subdomains - e.g., imitation, emotion, trait inference, etc. By integrating more domaingeneral and semantic control mechanisms into our model of social cognition, rather than minimising their role or ignoring them completely, we aim to harness the benefits from prior literature that characterises the contribution of a highly developed and powerful set of executive functions (Corbetta et al., 2008; Duncan, 2010; Lambon Ralph et al., 2016). We are not suggesting that social cognition would be any less sophisticated or interesting if it were not to rely exclusively on domain-specific processes (Spunt and Adolphs, 2017). 
By looking at a particular test case - the study of automatic imitation - it is easy to see how the pursuit of domain-specific processes may have overshadowed a role of more generalisable systems. Although researchers may be ultimately aiming for the same end, which is to understand cognitive and brain mechanisms that underpin specific social behaviours, there may have been misalignment between attempts to understand stimulus specificity and mechanism specificity. By emphasising the potential contribution of domain-general processes, we provide a reminder to clearly distinguish between the type of information in the environment (social or otherwise) and the type of mechanism that processes such information (i.e., the level of selectivity).

\section{How can the CSC framework guide future social cognition research?}

We offer four recommendations for future social cognition research guided by the CSC framework. First, and quite simply, we propose that when alternative models are being formulated, it would be useful to at least consider the concepts of representation and control, and the degree to which they are dissociable. Indeed, providing clear definitions of a model's architecture (including the associated neuroanatomy) and component processes enhances the ability to compare and contrast one theory to another (Gray, 2017). Many of the social cognition theories covered in this paper do not make explicit reference to terms such as these, and we suggest they may benefit from doing so. It could, for example, be particularly important for understanding commonalities and differences in the functions ascribed to certain brain regions. As outlined in Figure 2, diagrammatic illustration of model spaces can help researchers communicate in a common language. To be clear, though, we are not proposing that the CSC framework and the associated terms are the only way to characterise social cognition. Rather, much like in many other domains of research, we are suggesting that investigators from the 
social cognitive neurosciences could take steps towards developing formalised approaches that aid effective and informative comparison of models and ideas (Lenartowicz et al., 2010; Poldrack et al., 2011).

Second, we argue against an a priori need for domain-specific social processes. Rather, we suggest greater consideration needs to be given to a role of more generalizable systems and processes which operate in social contexts because they operate in every context (to some extent). Only when more general mechanisms cannot explain findings, may it be sensible to consider domain-specific "social" processes. For example, future research into executive processes in social cognition should explicitly model, and empirically examine, the role of domain-general control alongside any proposed form of domain-specific "social control" (see Section 4.2 for practical examples; Brass et al., 2009; Brass and Heyes, 2005; de Guzman et al., 2016; Sowden and Shah, 2014; Spengler et al., 2009; Wang and Hamilton, 2012). This also includes acknowledging the possibility that domain-general control processes interact with domain-specific social representations (Darda et al., 2018; Ramsey, 2018). Such a position statement reinforces the important distinction between the 'socialness' of information in our environment and that of mental processes. That is, social information and processes (e.g., faces, displays of emotion, social judgments etc.) are no less social if they are partly underpinned by mental processes that operate in many domains (i.e., both social and non-social contexts). Although this distinction appears to be an obvious point to make, and indeed, it has been made before (Adolphs, 2009), its significance for theory development in social cognitive neuroscience is frequently underappreciated. A third influence on future research is the potential for the CSC framework to inform cognitive models that account for atypical or disordered social cognition, including Autism Spectrum Disorder and schizophrenia as well as acquired social 
dysfunction observed following stroke, and in neurodegenerative disease. The simple distinction between representation and control has been proven to be clinically-relevant in the case of central semantic disorders. Patients with quantitatively similar panmodal semantic impairments have been shown to dissociate on the basis of qualitative error patterns that are consistent with either degraded/lost representations or dysregulated access to representations. Disorders of representation are associated with bilateral ATL pathology, while semantic control impairments arise following frontal and/or temporoparietal damage (Jefferies and Lambon Ralph, 2006; Thompson et al., 2016). It might also be interesting to consider whether future research might similarly dissociate social disorders on the basis of representation versus control impairments. Some insight comes from neuropsychological investigation of frontotemporal dementia (FTD) where apparently similar clinical presentations of social dysfunction arise in the context of different patterns of brain atrophy and different aetiologies (Binney et al., 2016a; Kamminga et al., 2015). It is now becoming apparent that in FTD variants with more prominent frontal lobe damage, the social impairments can be linked to deficits in executive function, while patients with greater temporal lobe than frontal lobe damage demonstrate a much weaker association (Healey and Grossman, 2018; Kamminga et al., 2015). In addition, in each of these disorders or diseases, it may be the interaction between representation and control that operates in an atypical manner. As a consequence, when tested in isolation, systems for representation and control could operate in a perfectly "normal" manner, whilst these individuals would still have atypical profile of cognitive function overall.

Finally, the current paper was focussed upon models of mature neurocognitive systems. We did not consider, in any detail, the emergence of social cognitive processes (Weigelt et al., 2014). However, we recognise potential for our proposal to aid in the 
advancement of neurocognitive models of social development. In particular, we argue that because social cognition is a case of semantic cognition then, over the course of development, the former should emerge from the latter. Such a proposal is consistent with the Neuroconstructivist and Neuroemergentist perspectives (D'Souza and Karmiloff-Smith, 2016; Hernandez et al., 2019; Karmiloff-Smith, 2015, 2006), which posit that the development of complex cognition, including social cognition, involves the combination of relatively simpler antecedent cognitive building blocks. A testable prediction that arises from this is that semantic and social cognition might be less easily distinguishable at earlier than later stages of development, and this may manifest in either behavioural patterns or in the engagement of brain networks.

\section{Concluding remarks}

A major challenge for the cognitive sciences is to characterise how we understand others and coordinate our behaviour to achieve mutually beneficial outcomes (Frith and Frith, 2010). In the above, we have outlined a novel theoretical framework for understanding social behaviour. Counter to a recent trend in delineating highly domainspecific models, this approach delivers clear foundational principles that can be generalised to a number of social phenomena, and can be translated into straightforward and testable predictions. Moreover, with time, it may emerge as having great potential to influence understanding of social impairments and the development of associated interventions. Alongside this framework, we provide suggestions of how to develop formalised approaches that could aid effective and informative comparison of models and ideas in the domain of social neuroscience, and cognitive science more generally. In sum, by treating social cognition as just one of the many ways in which we gather meaning from the world, rather than a special case, there is potential to shine 
new light on the cognitive and neurobiological mechanisms that underpin social information processing, and radically advance our understanding of human interactions, both in health and in disease. 


\section{References}

Abel, T.J., Rhone, A.E., Nourski, K. V, Howard 3rd, M.A., Tranel, D., 2015. Investigating the Anterior Temporal Lobe With Direct Intracranial Recordings. Neurosurgery 62 Suppl 1, 185-189. https://doi.org/10.1227/NEU.0000000000000789

Adolphs, R., 2010. Conceptual challenges and directions for social neuroscience. Neuron 65, 752-767. https://doi.org/10.1016/j.neuron.2010.03.006

Adolphs, R., 2009. The social brain: neural basis of social knowledge. Annu. Rev. Psychol. 60, 693-716. https://doi.org/10.1146/annurev.psych.60.110707.163514

Adolphs, R., 2002. Neural systems for recognizing emotion. Curr. Opin. Neurobiol. 12, 169-177. https://doi.org/10.1016/S0959-4388(02)00301-X

Amodio, D.M., 2019. Social Cognition 2.0: An Interactive Memory Systems Account. Trends Cogn. Sci. 23, 21-33. https://doi.org/10.1016/J.TICS.2018.10.002

Badre, D., 2008. Cognitive control, hierarchy, and the rostro-caudal organization of the frontal lobes. Trends Cogn. Sci. 12, 193-200. https://doi.org/10.1016/J.TICS.2008.02.004

Badre, D., Poldrack, R.A., Paré-Blagoev, E.J., Insler, R.Z., Wagner, A.D., 2005. Dissociable Controlled Retrieval and Generalized Selection Mechanisms in Ventrolateral Prefrontal Cortex. Neuron 47, 907-918. https://doi.org/10.1016/J.NEURON.2005.07.023

Badre, D., Wagner, A.D., 2007. Left ventrolateral prefrontal cortex and the cognitive control of memory. Neuropsychologia 45, 2883-2901. https://doi.org/10.1016/J.NEUROPSYCHOLOGIA.2007.06.015

Bajada, C.J., Haroon, H.A., Azadbakht, H., Parker, G.J.M., Lambon Ralph, M.A., Cloutman, L.L., 2017. The tract terminations in the temporal lobe: Their location and associated functions. Cortex. 97, 277-290. 
https://doi.org/10.1016/j.cortex.2016.03.013

Bar, M., 2004. Visual objects in context. Nat. Rev. Neurosci. 5, 617.

Bargh, J.A., 1994. The four horsemen of automaticity: Intention, awareness, efficiency, and control as separate issues, in: Wyer, R., Srull, T. (Eds.), Handbook of Social Cognition. Lawrence Erlbaum.

Bargh, J.A., 1989. Conditional automaticity: Varieties of automatic influence in social perception and cognition., in: Unintended Thought. Guilford Press, New York, NY, US, pp. 3-51.

Beck, D.M., Kastner, S., 2009. Top-down and bottom-up mechanisms in biasing competition in the human brain. Vision Res. 49, 1154-1165. https://doi.org/10.1016/j.visres.2008.07.012

Binney, R.J., Ashaie, S.A., Zuckerman, B.M., Hung, J., Reilly, J., 2018. Frontotemporal stimulation modulates semantically-guided visual search during confrontation naming: A combined tDCS and eye tracking investigation. Brain Lang. 180-182, 1423. https://doi.org/10.1016/J.BANDL.2018.04.004

Binney, R.J., Embleton, K. V, Parker, G.J.M., Jefferies, E., Lambon Ralph, M.A., 2010. The Ventral and Inferolateral Aspects of the Anterior Temporal Lobe Are Crucial in Semantic Memory: Evidence from a Novel Direct Comparison of DistortionCorrected fMRI, rTMS, and Semantic Dementia. Cereb. Cortex 20, 2728-2738. https://doi.org/10.1093/cercor/bhq019

Binney, R.J., Henry, M.L., Babiak, M., Pressman, P.S., Santos-Santos, M.A., Narvid, J., Mandelli, M.L., Strain, P.J., Miller, B.L., Rankin, K.P., Rosen, H.J., Gorno-Tempini, M.L., 2016a. Reading words and other people: A comparison of exception word, familiar face and affect processing in the left and right temporal variants of primary progressive aphasia. Cortex. 82, 147-163. 
https://doi.org/10.1016/j.cortex.2016.05.014

Binney, R.J., Hoffman, P., Lambon Ralph, M.A., 2016b. Mapping the Multiple Graded Contributions of the Anterior Temporal Lobe Representational Hub to Abstract and Social Concepts: Evidence from Distortion-corrected fMRI. Cereb. Cortex 26, 42274241. https://doi.org/10.1093/cercor/bhw260

Binney, R.J., Lambon Ralph, M.A., 2015. Using a combination of fMRI and anterior temporal lobe rTMS to measure intrinsic and induced activation changes across the semantic cognition network. Neuropsychologia 76, 170-181. https://doi.org/10.1016/J.NEUROPSYCHOLOGIA.2014.11.009

Binney, R.J., Parker, G.J.M., Lambon Ralph, M.A., 2012. Convergent Connectivity and Graded Specialization in the Rostral Human Temporal Lobe as Revealed by Diffusion-Weighted Imaging Probabilistic Tractography. J. Cogn. Neurosci. 24, 1998-2014. https://doi.org/10.1162/jocn_a_00263

Bozeat, S., Lambon Ralph, M.A., Patterson, K., Garrard, P., Hodges, J.R., 2000. Non-verbal semantic impairment in semantic dementia. Neuropsychologia 38, 1207-1215. https://doi.org/10.1016/S0028-3932(00)00034-8

Brass, M., Heyes, C., 2005. Imitation: is cognitive neuroscience solving the correspondence problem? Trends Cogn. Sci. 9, 489-495. https://doi.org/10.1016/J.TICS.2005.08.007

Brass, M., Ruby, P., Spengler, S., 2009. Inhibition of imitative behaviour and social cognition. Philos. Trans. R. Soc. Lond. B. Biol. Sci. 364, 2359-2367. https://doi.org/10.1098/rstb.2009.0066

Brown, S., Schafer, E.A., 1888. An Investigation into the Functions of the Occipital and Temporal Lobes of the Monkey's Brain. Philos. Trans. R. Soc. London. B 179, 303327. 
Cabeza, R., Moscovitch, M., 2013. Memory Systems, Processing Modes, and Components: Functional Neuroimaging Evidence. Perspect. Psychol. Sci. 8, 49-55. https://doi.org/10.1177/1745691612469033

Cacioppo, J.T., Berntson, G.G., 1992. Social psychological contributions to the decade of the brain: Doctrine of multilevel analysis. Am. Psychol. https://doi.org/10.1037/0003-066X.47.8.1019

Cacioppo, J.T., Decety, J., 2011. Social neuroscience: challenges and opportunities in the study of complex behavior. Ann. N. Y. Acad. Sci. 1224, 162-173. https://doi.org/10.1111/j.1749-6632.2010.05858.x

Carruthers, P., 2017. Mindreading in adults: evaluating two-systems views. Synthese 194.

Carruthers, P., 2016. Two Systems for Mindreading? Rev. Philos. Psychol. 7, 141-162. https://doi.org/10.1007/s13164-015-0259-y

Caspers, S., Zilles, K., Laird, A.R., Eickhoff, S.B., 2010. ALE meta-analysis of action observation and imitation in the human brain. Neuroimage 50, 1148-1167. https://doi.org/10.1016/J.NEUROIMAGE.2009.12.112

Chan, A.M., Baker, J.M., Eskandar, E., Schomer, D., Ulbert, I., Marinkovic, K., Cash, S.S., Halgren, E., 2011. First-Pass Selectivity for Semantic Categories in Human Anteroventral Temporal Lobe. J. Neurosci. 31, 18119 LP - 18129. https://doi.org/10.1523/JNEUROSCI.3122-11.2011

Chan, D., Whitwell, J., Barnes, J., Fox, N.C., Scahill, R., Anderson, V., Rossor, M.N., Barkhof, F., Scheltens, P., Pijnenburg, Y., Stevens, J.M., 2009. The clinical profile of right temporal lobe atrophy. Brain 132, 1287-1298. https://doi.org/10.1093/brain/awp037

Chiou, R., Humphreys, G.F., Jung, J., Lambon Ralph, M.A., 2018. Controlled semantic 
cognition relies upon dynamic and flexible interactions between the executive "semantic control" and hub-and-spoke "semantic representation" systems. Cortex. 103, 100-116. https://doi.org/10.1016/j.cortex.2018.02.018

Coad, B.M., Postans, M., Hodgetts, C.J., Muhlert, N., Graham, K.S., Lawrence, A.D., 2017. Structural connections support emotional connections: Uncinate Fasciculus microstructure is related to the ability to decode facial emotion expressions. Neuropsychologia. https://doi.org/10.1016/J.NEUROPSYCHOLOGIA.2017.11.006

Coccia, M., Bartolini, M., Luzzi, S., Provinciali, L., Lambon Ralph, M.A., 2004. Semantic memory is an amodal, dynamic system: Evidence from the interaction of naming and object use in semantic dementia. Cogn. Neuropsychol. 21, 513-527. https://doi.org/10.1080/02643290342000113

Corbett, F., Jefferies, E., Ehsan, S., Lambon Ralph, M.A., 2009. Different impairments of semantic cognition in semantic dementia and semantic aphasia: evidence from the non-verbal domain. Brain 132, 2593-2608. https://doi.org/10.1093/brain/awp146

Corbetta, M., Patel, G., Shulman, G.L., 2008. The Reorienting System of the Human Brain: From Environment to Theory of Mind. Neuron 58, 306-324. https://doi.org/10.1016/J.NEURON.2008.04.017

Corbetta, M., Shulman, G.L., 2002. Control of goal-directed and stimulus-driven attention in the brain. Nat. Rev. Neurosci. 3, 201.

Cross, K.A., Torrisi, S., Reynolds Losin, E.A., Iacoboni, M., 2013. Controlling automatic imitative tendencies: Interactions between mirror neuron and cognitive control systems. Neuroimage 83, 493-504. https://doi.org/10.1016/J.NEUROIMAGE.2013.06.060

Crutch, S.J., Troche, J., Reilly, J., Ridgway, G.R., 2013. Abstract conceptual feature ratings: 
the role of emotion, magnitude, and other cognitive domains in the organization of abstract conceptual knowledge. Front. Hum. Neurosci. 7, 186.

https://doi.org/10.3389/fnhum.2013.00186

Culham, J.C., Valyear, K.F., 2006. Human parietal cortex in action. Curr. Opin. Neurobiol. 16, 205-212. https://doi.org/10.1016/J.CONB.2006.03.005

D’Souza, D., Karmiloff-Smith, A., 2016. Why a developmental perspective is critical for understanding human cognition. Behav. Brain Sci. 39, e122. https://doi.org/10.1017/S0140525X15001569

Damasio, H., Grabowski, T.J., Tranel, D., Hichwa, R.D., Damasio, A.R., 1996. A neural basis for lexical retrieval. Nature 380, 499-505. https://doi.org/10.1038/380499a0

Darda, K.M., Butler, E.E., Ramsey, R., 2018. Functional Specificity and Sex Differences in the Neural Circuits Supporting the Inhibition of Automatic Imitation. J. Cogn. Neurosci. 30, 914-933. https://doi.org/10.1162/jocn_a_01261

Davey, J., Rueschemeyer, S.-A., Costigan, A., Murphy, N., Krieger-Redwood, K., Hallam, G., Jefferies, E., 2015. Shared neural processes support semantic control and action understanding. Brain Lang. 142, 24-35. https://doi.org/10.1016/J.BANDL.2015.01.002

Davey, J., Thompson, H.E., Hallam, G., Karapanagiotidis, T., Murphy, C., De Caso, I., Krieger-Redwood, K., Bernhardt, B.C., Smallwood, J., Jefferies, E., 2016. Exploring the role of the posterior middle temporal gyrus in semantic cognition: Integration of anterior temporal lobe with executive processes. Neuroimage 137, 165-177. https://doi.org/10.1016/J.NEUROIMAGE.2016.05.051

de Guzman, M., Bird, G., Banissy, M., Catmur, C., 2016. Self-other control processes in social cognition: from imitation to empathy. Philos. Trans. R. Soc. B Biol. Sci. 371, 20150079. https://doi.org/10.1098/rstb.2015.0079 
Dehaene, S., Cohen, L., 2011. The unique role of the visual word form area in reading. Trends Cogn. Sci. 15, 254-262. https://doi.org/10.1016/J.TICS.2011.04.003

Desimone, R., Duncan, J., 1995. Neural Mechanisms of Selective Visual Attention. Annu. Rev. Neurosci. 18, 193-222.

https://doi.org/10.1146/annurev.ne.18.030195.001205

Devlin, J.T., Matthews, P.M., Rushworth, M.F.S., 2003. Semantic Processing in the Left Inferior Prefrontal Cortex: A Combined Functional Magnetic Resonance Imaging and Transcranial Magnetic Stimulation Study. J. Cogn. Neurosci. 15, 71-84. https://doi.org/10.1162/089892903321107837

Duncan, J., 2010. The multiple-demand (MD) system of the primate brain: mental programs for intelligent behaviour. Trends Cogn. Sci. 14, 172-179. https://doi.org/10.1016/J.TICS.2010.01.004

Edwards-Lee, T., Miller, B., Benson, D., Cummings, J., Russell, G., Boone, K., Mena, I., 1997. The temporal variant of frontotemporal dementia. Brain 120,1027-1040.

Epstein, R., Harris, A., Stanley, D., Kanwisher, N., 1999. The Parahippocampal Place Area: Recognition, Navigation, or Encoding? Neuron 23, 115-125. https://doi.org/10.1016/S0896-6273(00)80758-8

Fedorenko, E., Duncan, J., Kanwisher, N., 2012. Language-Selective and Domain-General Regions Lie Side by Side within Broca's Area. Curr. Biol. 22, 2059-2062. https://doi.org/https://doi.org/10.1016/j.cub.2012.09.011

Frith, C.D., Frith, U., 2011. Mechanisms of Social Cognition. Annu. Rev. Psychol. 63, 287313. https://doi.org/10.1146/annurev-psych-120710-100449

Frith, C.D., Frith, U., 1999. Interacting Minds--A Biological Basis. Science (80-. ). 286, 1692 LP - 1695. https://doi.org/10.1126/science.286.5445.1692

Frith, U., Frith, C., 2010. The social brain: allowing humans to boldly go where no other 
species has been. Philos. Trans. R. Soc. B Biol. Sci. 365, 165-176.

https://doi.org/10.1098/rstb.2009.0160

Frith, U., Frith, C.D., 2003. Development and neurophysiology of mentalizing. Philos.

Trans. R. Soc. Lond. B. Biol. Sci. 358, 459-473.

https://doi.org/10.1098/rstb.2002.1218

Gainotti, G., 2015. Is the difference between right and left ATLs due to the distinction between general and social cognition or between verbal and non-verbal representations? Neurosci. Biobehav. Rev. 51, 296-312.

https://doi.org/10.1016/J.NEUBIOREV.2015.02.004

Gallate, J., Wong, C., Ellwood, S., Chi, R., Snyder, A., 2011. Noninvasive brain stimulation reduces prejudice scores on an implicit association test. Neuropsychology. https://doi.org/10.1037/a0021102

Gorno-Tempini, M.L., Hillis, A.E., Weintraub, S., Kertesz, A., Mendez, M., Cappa, S.F., Ogar, J.M., Rohrer, J.D., Black, S., Boeve, B.F., Manes, F., Dronkers, N.F., Vandenberghe, R., Rascovsky, K., Patterson, K., Miller, B.L., Knopman, D.S., Hodges, J.R., Mesulam, M.M., Grossman, M., 2011. Classification of primary progressive aphasia and its variants. Neurology 76, 1006 LP - 1014. https://doi.org/10.1212/WNL.0b013e31821103e6

Gough, P.M., Nobre, A.C., Devlin, J.T., 2005. Dissociating linguistic processes in the left inferior frontal cortex with transcranial magnetic stimulation. J. Neurosci. 25, 80108016. https://doi.org/10.1523/JNEUROSCI.2307-05.2005

Gowen, E., Poliakoff, E., 2012. How does visuomotor priming differ for biological and non-biological stimuli? A review of the evidence. Psychol. Res. 76, 407-420. https://doi.org/10.1007/s00426-011-0389-5

Gray, K., 2017. How to Map Theory: Reliable Methods Are Fruitless Without Rigorous Theory. Perspect. Psychol. Sci. 12, 731-741. 
https://doi.org/10.1177/1745691617691949

Guo, C.C., Gorno-Tempini, M.L., Gesierich, B., Henry, M., Trujillo, A., Shany-Ur, T., Jovicich, J., Robinson, S.D., Kramer, J.H., Rankin, K.P., Miller, B.L., Seeley, W.W., 2013. Anterior temporal lobe degeneration produces widespread network-driven dysfunction. Brain 136, 2979-2991. https://doi.org/10.1093/brain/awt222

Healey, M.L., Grossman, M., 2018. Cognitive and Affective Perspective-Taking: Evidence for Shared and Dissociable Anatomical Substrates. Front. Neurol. 9, 491. https://doi.org/10.3389/fneur.2018.00491

Hernandez, A.E., Claussenius-Kalman, H.L., Ronderos, J., Castilla-Earls, A.P., Sun, L., Weiss, S.D., Young, D.R., 2019. Neuroemergentism: A framework for studying cognition and the brain. J. Neurolinguistics 49, 214-223. https://doi.org/10.1016/J.JNEUROLING.2017.12.010

Heyes, C., 2011. Automatic imitation. Psychol. Bull. https://doi.org/10.1037/a0022288

Hickok, G., 2013. Do mirror neurons subserve action understanding? Neurosci. Lett. 540, 56-58. https://doi.org/10.1016/J.NEULET.2012.11.001

Hickok, G., Hauser, M., 2010. (Mis)understanding mirror neurons. Curr. Biol. 20, R593R594. https://doi.org/10.1016/j.cub.2010.05.047

Hodges, J.R., Patterson, K., Oxbury, S., Funnell, E., 1992. Semantic Dementia: Progressive fluent aphasia with temporal lobe atrophy, Brain : a journal of neurology. https://doi.org/10.1093/brain/115.6.1783

Hoffman, P., Binney, R.J., Lambon Ralph, M.A., 2015. Differing contributions of inferior prefrontal and anterior temporal cortex to concrete and abstract conceptual knowledge. Cortex 63, 250-266. https://doi.org/https://doi.org/10.1016/j.cortex.2014.09.001

Hoffman, P., Lambon Ralph, M.A., 2018. From percept to concept in the ventral temporal 
lobes: Graded hemispheric specialisation based on stimulus and task. Cortex 101, 107-118. https://doi.org/10.1016/J.CORTEX.2018.01.015

Iacoboni, M., 2008. Imitation, Empathy, and Mirror Neurons. Annu. Rev. Psychol. 60, 653-670. https://doi.org/10.1146/annurev.psych.60.110707.163604

Irish, M., Hornberger, M., Lah, S., Miller, L., Pengas, G., Nestor, P.J., Hodges, J.R., Piguet, O., 2011. Profiles of recent autobiographical memory retrieval in semantic dementia, behavioural-variant frontotemporal dementia, and Alzheimer's disease. Neuropsychologia 49, 2694-2702. https://doi.org/10.1016/J.NEUROPSYCHOLOGIA.2011.05.017

Jefferies, E., 2013. The neural basis of semantic cognition: Converging evidence from neuropsychology, neuroimaging and TMS. Cortex 49, 611-625. https://doi.org/https://doi.org/10.1016/j.cortex.2012.10.008

Jefferies, E., Lambon Ralph, M.A., 2006. Semantic impairment in stroke aphasia versus semantic dementia: a case-series comparison. Brain 129, 2132-2147. https://doi.org/10.1093/brain/awl153

Jung, J., Cloutman, L.L., Binney, R.J., Ralph, M.A.L., 2017. The structural connectivity of higher order association cortices reflects human functional brain networks. Cortex A J. Devoted to Study Nerv. Syst. Behav. https://doi.org/10.1016/j.cortex.2016.08.011

Kamminga, J., Kumfor, F., Burrell, J.R., Piguet, O., Hodges, J.R., Irish, M., 2015. Differentiating between right-lateralised semantic dementia and behaviouralvariant frontotemporal dementia: an examination of clinical characteristics and emotion processing. J. Neurol. Neurosurg. \&amp;amp; Psychiatry 86, 1082 LP 1088. https://doi.org/10.1136/jnnp-2014-309120

Kanwisher, N., 2010. Functional specificity in the human brain: A window into the 
functional architecture of the mind. Proc. Natl. Acad. Sci. 107, 11163 LP - 11170. https://doi.org/10.1073/pnas.1005062107

Karmiloff-Smith, A., 2015. An Alternative to Domain-general or Domain-specific Frameworks for Theorizing about Human Evolution and Ontogenesis. AIMS Neurosci. https://doi.org/10.3934/Neuroscience.2015.2.91

Karmiloff-Smith, A., 2006. The tortuous route from genes to behavior: A neuroconstructivist approach. Cogn. Affect. Behav. Neurosci. 6, 9-17. https://doi.org/10.3758/CABN.6.1.9

Kilner, J.M., 2011. More than one pathway to action understanding. Trends Cogn. Sci. 15, 352-357. https://doi.org/10.1016/j.tics.2011.06.005

Klüver, H., Bucy, P.C., 1939. Preliminary analysis of functions of the temporal lobes in monkeys. Arch. Neurol. Psychiatry 42, 979-1000. https://doi.org/10.1001/archneurpsyc.1939.02270240017001

Kousta, S.-T., Vigliocco, G., Vinson, D.P., Andrews, M., Del Campo, E., 2011. The representation of abstract words: Why emotion matters. J. Exp. Psychol. Gen. https://doi.org/10.1037/a0021446

Kumfor, F., Landin-Romero, R., Devenney, E., Hutchings, R., Grasso, R., Hodges, J.R., Piguet, 0., 2016. On the right side? A longitudinal study of left- versus rightlateralized semantic dementia. Brain 139, 986-998. https://doi.org/10.1093/brain/awv387

Lambon Ralph, M.A., 2014. Neurocognitive insights on conceptual knowledge and its breakdown. Philos. Trans. R. Soc. Lond. B. Biol. Sci. 369, 20120392. https://doi.org/10.1098/rstb.2012.0392

Lambon Ralph, M.A., Jefferies, E., Patterson, K., Rogers, T.T., 2016. The neural and computational bases of semantic cognition. Nat. Rev. Neurosci. 18, 42. 
Lambon Ralph, M.A., McClelland, J.L., Patterson, K., Galton, C.J., Hodges, J.R., 2001. No Right to Speak? The Relationship between Object Naming and Semantic Impairment:Neuropsychological Evidence and a Computational Model. J. Cogn. Neurosci. 13, 341-356. https://doi.org/10.1162/08989290151137395

Lenartowicz, A., Kalar, D.J., Congdon, E., Poldrack, R.A., 2010. Towards an Ontology of Cognitive Control. Top. Cogn. Sci. 2, 678-692. https://doi.org/10.1111/j.17568765.2010.01100.x

Leshinskaya, A., Contreras, J.M., Caramazza, A., Mitchell, J.P., 2017. Neural Representations of Belief Concepts: A Representational Similarity Approach to Social Semantics. Cereb. Cortex 27, 344-357. https://doi.org/10.1093/cercor/bhw401

Lieberman, M.D., 2006. Social Cognitive Neuroscience: A Review of Core Processes. Annu. Rev. Psychol. 58, 259-289. https://doi.org/10.1146/annurev.psych.58.110405.085654

Luzzi, S., Snowden, J.S., Neary, D., Coccia, M., Provinciali, L., Lambon Ralph, M.A., 2007. Distinct patterns of olfactory impairment in Alzheimer's disease, semantic dementia, frontotemporal dementia, and corticobasal degeneration. Neuropsychologia 45, 1823-1831. https://doi.org/10.1016/J.NEUROPSYCHOLOGIA.2006.12.008

Martin, A., 2006. The Representation of Object Concepts in the Brain. Annu. Rev. Psychol. 58, 25-45. https://doi.org/10.1146/annurev.psych.57.102904.190143 Melnikoff, D.E., Bargh, J.A., 2018. The Mythical Number Two. Trends Cogn. Sci. 22, 280293. https://doi.org/10.1016/j.tics.2018.02.001

Miller, E.K., 2000. The prefontral cortex and cognitive control. Nat. Rev. Neurosci. 1, 5965. https://doi.org/10.1038/35036228 
Mion, M., Patterson, K., Acosta-Cabronero, J., Pengas, G., Izquierdo-Garcia, D., Hong, Y.T., Fryer, T.D., Williams, G.B., Hodges, J.R., Nestor, P.J., 2010. What the left and right anterior fusiform gyri tell us about semantic memory. Brain 133, 3256-3268. https://doi.org/10.1093/brain/awq272

Moll, J., Zahn, R., de Oliveira-Souza, R., Krueger, F., Grafman, J., 2005. The neural basis of human moral cognition. Nat. Rev. Neurosci. 6, 799.

Moors, A., De Houwer, J., 2006. Automaticity: A Theoretical and Conceptual Analysis. Psychol. Bull. https://doi.org/10.1037/0033-2909.132.2.297

Mummery, C.J., Patterson, K., Price, C.J., Ashburner, J., Frackowiak, R.S.J., Hodges, J.R., 2000. A voxel-based morphometry study of semantic dementia: Relationship between temporal lobe atrophy and semantic memory. Ann. Neurol. 47, 36-45. https://doi.org/10.1002/1531-8249(200001)47:1<36::AID-ANA8>3.0.CO;2-L

Nagel, I.E., Schumacher, E.H., Goebel, R., D’Esposito, M., 2008. Functional MRI investigation of verbal selection mechanisms in lateral prefrontal cortex. Neuroimage 43, 801-807. https://doi.org/10.1016/j.neuroimage.2008.07.017 Nestor, P., Fryer, T., R Hodges, J., 2005. Declarative memory impairments in Alzheimer's disease and semantic dementia, NeuroImage.

Noonan, K.A., Jefferies, E., Corbett, F., Lambon Ralph, M.A., 2009. Elucidating the Nature of Deregulated Semantic Cognition in Semantic Aphasia: Evidence for the Roles of Prefrontal and Temporo-parietal Cortices. J. Cogn. Neurosci. 22, 1597-1613. https://doi.org/10.1162/jocn.2009.21289

Noonan, K.A., Jefferies, E., Visser, M., Lambon Ralph, M.A., 2013. Going beyond Inferior Prefrontal Involvement in Semantic Control: Evidence for the Additional Contribution of Dorsal Angular Gyrus and Posterior Middle Temporal Cortex. J. Cogn. Neurosci. 25, 1824-1850. https://doi.org/10.1162/jocn_a_00442 
Olson, I.R., McCoy, D., Klobusicky, E., Ross, L.A., 2013. Social cognition and the anterior temporal lobes: a review and theoretical framework. Soc. Cogn. Affect. Neurosci. 8, 123-133. https://doi.org/10.1093/scan/nss119

Olson, I.R., Plotzker, A., Ezzyat, Y., 2007. The Enigmatic temporal pole: a review of findings on social and emotional processing. Brain 130, 1718-1731. https://doi.org/10.1093/brain/awm052

Papinutto, N., Galantucci, S., Mandelli, M.L., Gesierich, B., Jovicich, J., Caverzasi, E., Henry, R.G., Seeley, W.W., Miller, B.L., Shapiro, K.A., Gorno-Tempini, M.L., 2016. Structural connectivity of the human anterior temporal lobe: A diffusion magnetic resonance imaging study. Hum. Brain Mapp. 37, 2210-2222. https://doi.org/10.1002/hbm.23167

Perry, R.J., Rosen, H.R., Kramer, J.H., Beer, J.S., Levenson, R.L., Miller, B.L., 2001. Hemispheric dominance for emotions, empathy and social behaviour: Evidence from right and left handers with frontotemporal dementia, Neurocase. https://doi.org/10.1093/neucas/7.2.145

Piwnica-Worms, K.E., Omar, R., Hailstone, J.C., Warren, J.D., 2010. Flavour processing in semantic dementia. Cortex. 46, 761-768. https://doi.org/10.1016/j.cortex.2009.07.002

Plaut, D.C., 2002. Graded modality-specific specialisation in semantics: A computational account of optic aphasia. Cogn. Neuropsychol. 19, 603-639. https://doi.org/10.1080/02643290244000112

Pobric, G., Jefferies, E., Lambon Ralph, M.A., 2010. Category-Specific versus CategoryGeneral Semantic Impairment Induced by Transcranial Magnetic Stimulation. Curr. Biol. 20, 964-968. https://doi.org/10.1016/J.CUB.2010.03.070

Pobric, G., Jefferies, E., Ralph, M.A.L., 2007. Anterior temporal lobes mediate semantic 
representation: mimicking semantic dementia by using rTMS in normal participants. Proc. Natl. Acad. Sci. U. S. A. 104, 20137-20141.

https://doi.org/10.1073/pnas.0707383104

Pobric, G., Lambon Ralph, M.A., Zahn, R., 2015. Hemispheric Specialization within the Superior Anterior Temporal Cortex for Social and Nonsocial Concepts. J. Cogn. Neurosci. 28, 351-360. https://doi.org/10.1162/jocn_a_00902

Poldrack, R., Kittur, A., Kalar, D., Miller, E., Seppa, C., Gil, Y., Parker, D., Sabb, F., Bilder, R., 2011. The Cognitive Atlas: Toward a Knowledge Foundation for Cognitive Neuroscience . Front. Neuroinformatics .

Posner, M.I., Snyder, C.R.R., 1975. Attention and cognitive control, in: Solso, R.L. (Ed.), Information Processing and Cognition: The Loyola Symposium. Lawrence Erlbaum. Ramsey, R., 2018. What are reaction time indices of automatic imitation measuring? Conscious. Cogn. 65, 240-254. https://doi.org/10.1016/J.CONCOG.2018.08.006

Reilly, J., Garcia, A., Binney, R.J., 2016. Does the sound of a barking dog activate its corresponding visual form? An fMRI investigation of modality-specific semantic access. Brain Lang. 159, 45-59. https://doi.org/10.1016/j.bandl.2016.05.006

Rice, G.E., Caswell, H., Moore, P., Hoffman, P., Lambon Ralph, M.A., 2018a. The Roles of Left Versus Right Anterior Temporal Lobes in Semantic Memory: A Neuropsychological Comparison of Postsurgical Temporal Lobe Epilepsy Patients. Cereb. Cortex 28, 1487-1501. https://doi.org/10.1093/cercor/bhx362

Rice, G.E., Hoffman, P., Binney, R.J., Lambon Ralph, M.A., 2018b. Concrete versus abstract forms of social concept: an fMRI comparison of knowledge about people versus social terms. Philos. Trans. R. Soc. Lond. B. Biol. Sci. 373, 20170136. https://doi.org/10.1098/rstb.2017.0136

Rice, G.E., Hoffman, P., Lambon Ralph, M.A., 2015. The Roles of Left Versus Right 
Anterior Temporal Lobes in Conceptual Knowledge: An ALE Meta-analysis of 97

Functional Neuroimaging Studies. Cereb. Cortex 25, 4374-4391.

https://doi.org/10.1093/cercor/bhv024

Rogers, T.T., Lambon Ralph, M.A., Garrard, P., Bozeat, S., McClelland, J.L., Hodges, J.R., Patterson, K., 2004. Structure and Deterioration of Semantic Memory: A Neuropsychological and Computational Investigation. Psychol. Rev. https://doi.org/10.1037/0033-295X.111.1.205

Saffran, E.M., 2000. The Organization of Semantic Memory: In Support of a Distributed Model. Brain Lang. 71, 204-212. https://doi.org/10.1006/BRLN.1999.2251

Saxe, R., Kanwisher, N., 2003. People thinking about thinking people: The role of the temporo-parietal junction in “theory of mind.” Neuroimage 19, 1835-1842. https://doi.org/10.1016/S1053-8119(03)00230-1

Shiffrin, R., Schneider, W., 1977. Controlled and automatic human information processing: II. Perceptual learning, automatic attending and a general theory, Psychological Review. https://doi.org/10.1037/0033-295X.84.2.127

Shimotake, A., Matsumoto, R., Ueno, T., Kunieda, T., Saito, S., Hoffman, P., Kikuchi, T., Fukuyama, H., Miyamoto, S., Takahashi, R., Ikeda, A., Lambon Ralph, M.A., 2015. Direct Exploration of the Role of the Ventral Anterior Temporal Lobe in Semantic Memory: Cortical Stimulation and Local Field Potential Evidence From Subdural Grid Electrodes. Cereb. Cortex 25, 3802-3817. https://doi.org/10.1093/cercor/bhu262

Simmons, W.K., Martin, A., 2009. The anterior temporal lobes and the functional architecture of semantic memory. J. Int. Neuropsychol. Soc. 15, 645-649. https://doi.org/10.1017/S1355617709990348

Singer, T., Lamm, C., 2009. The Social Neuroscience of Empathy. Ann. N. Y. Acad. Sci. 
1156, 81-96. https://doi.org/10.1111/j.1749-6632.2009.04418.x

Skipper, L.M., Ross, L.A., Olson, I.R., 2011. Sensory and semantic category subdivisions within the anterior temporal lobes. Neuropsychologia 49, 3419-3429. https://doi.org/10.1016/j.neuropsychologia.2011.07.033

Snowden, J.S., Harris, J.M., Thompson, J.C., Kobylecki, C., Jones, M., Richardson, A.M., Neary, D., 2018. Semantic dementia and the left and right temporal lobes. Cortex 107, 188-203. https://doi.org/10.1016/J.CORTEX.2017.08.024

Sowden, S., Shah, P., 2014. Self-other control: a candidate mechanism for social cognitive function. Front. Hum. Neurosci. 8, 789. https://doi.org/10.3389/fnhum.2014.00789 Spengler, S., von Cramon, D.Y., Brass, M., 2009. Control of shared representations relies on key processes involved in mental state attribution. Hum. Brain Mapp. 30, 37043718. https://doi.org/10.1002/hbm.20800

Spunt, R.P., Adolphs, R., 2017. A new look at domain specificity: insights from social neuroscience. Nat. Rev. Neurosci. 18, 559.

Thompson-Schill, S.L., D’Esposito, M., Aguirre, G.K., Farah, M.J., 1997. Role of left inferior prefrontal cortex in retrieval of semantic knowledge: A reevaluation. Proc. Natl. Acad. Sci. 94, 14792 LP - 14797. https://doi.org/10.1073/pnas.94.26.14792

Thompson, H.E., Henshall, L., Jefferies, E., 2016. The role of the right hemisphere in semantic control: A case-series comparison of right and left hemisphere stroke. Neuropsychologia 85, 44-61. https://doi.org/10.1016/j.neuropsychologia.2016.02.030

Thompson, S.A., Patterson, K., Hodges, J.R., 2003. Left/right asymmetry of atrophy in semantic dementia. Neurology 61, 1196 LP - 1203. https://doi.org/10.1212/01.WNL.0000091868.28557.B8 Van Overwalle, F., 2009. Social cognition and the brain: A meta-analysis. Hum. Brain 
Mapp. 30, 829-858. https://doi.org/10.1002/hbm.20547

Vigliocco, G., Kousta, S.-T., Della Rosa, P.A., Vinson, D.P., Tettamanti, M., Devlin, J.T., Cappa, S.F., 2013. The Neural Representation of Abstract Words: The Role of Emotion. Cereb. Cortex 24, 1767-1777. https://doi.org/10.1093/cercor/bht025 Von Der Heide, R.J., Skipper, L.M., Klobusicky, E., Olson, I.R., 2013. Dissecting the uncinate fasciculus: disorders, controversies and a hypothesis. Brain 136, 16921707. https://doi.org/10.1093/brain/awt094

Wang, Y., Hamilton, A.F. de C., 2012. Social top-down response modulation (STORM): a model of the control of mimicry in social interaction. Front. Hum. Neurosci. 6, 153. https://doi.org/10.3389/fnhum.2012.00153

Weigelt, S., Koldewyn, K., Dilks, D.D., Balas, B., McKone, E., Kanwisher, N., 2014. Domainspecific development of face memory but not face perception. Dev. Sci. 17, 47-58. https://doi.org/10.1111/desc.12089

Whitney, C., Kirk, M., O'Sullivan, J., Lambon Ralph, M.A., Jefferies, E., 2011a. The neural organization of semantic control: TMS evidence for a distributed network in left inferior frontal and posterior middle temporal gyrus. Cereb. Cortex 21, 1066-1075. https://doi.org/10.1093/cercor/bhq180

Whitney, C., Kirk, M., O'Sullivan, J., Lambon Ralph, M.A., Jefferies, E., 2011b. Executive Semantic Processing Is Underpinned by a Large-scale Neural Network: Revealing the Contribution of Left Prefrontal, Posterior Temporal, and Parietal Cortex to Controlled Retrieval and Selection Using TMS. J. Cogn. Neurosci. 24, 133-147. https://doi.org/10.1162/jocn_a_00123

Wicker, B., Perrett, D.I., Baron-Cohen, S., Decety, J., 2003. Being the target of another's emotion: a PET study. Neuropsychologia 41, 139-146. https://doi.org/10.1016/S0028-3932(02)00144-6 
Zahn, R., Moll, J., Iyengar, V., Huey, E.D., Tierney, M., Krueger, F., Grafman, J., 2009. Social conceptual impairments in frontotemporal lobar degeneration with right anterior temporal hypometabolism. Brain. https://doi.org/10.1093/brain/awn343

Zahn, R., Moll, J., Krueger, F., Huey, E.D., Garrido, G., Grafman, J., 2007. Social concepts are represented in the superior anterior temporal cortex. Proc. Natl. Acad. Sci. 104, 6430 LP - 6435. https://doi.org/10.1073/pnas.0607061104 